\title{
Exploring Pornography Use in Secure Hospitals: A qualitative Analysis
}

\begin{tabular}{|r|l|}
\hline Journal: & Journal of Forensic Practice \\
\hline Manuscript ID & JFP-07-2019-0030.R1 \\
\hline Manuscript Type: & Research Paper \\
\hline Keywords: & pornography, secure hospitals, staff, patients, attitudes, decision making \\
\hline & \\
\end{tabular}

SCHOLARONE

Manuscripts 


\title{
Exploring Pornography Use in Secure Hospitals: A qualitative Analysis
}

\begin{abstract}
Purpose: This research paper reports findings from a qualitative analysis which explored pornography use in secure hospitals. The study aims to investigate what attitudes staff working in secure hospital have towards patients having access to pornography, how they make decisions regarding access to pornography and what factors they take into account during this process. This research is an extension of a prior quantitative research study (Mellor \& Duff, 2019).
\end{abstract}

Method: The study utilised a qualitative approach using semi-structured interviews to explore professionals' attitudes towards pornography use in a secure hospital. The sample comprised of six volunteers who had taken part in a previous research study-(Mellor \& Duff, 2019) requesting to discuss the topic area further. As such this research study was developed. Thematic analysis (Braun \& Clarke, 2006) was used to analyse the qualitative data and the Attitudes towards Pornography Scale (EvansDeCicci \& Cowan, 2001) was used to collect demographic information. Results: Six themes were identified from the transcripts. The first theme explores staff members' attitudes toward pornography. The second relates to the use of boundaries and monitoring of pornography. The third theme looks at the potential impact that pornography could have on the patient, either positive or negative. The fourth theme explores the extent to which patients are still considered as human beings, whereas the fifth 
theme explores the vulnerabilities that may make patients more at risk of being negatively influenced by pornography. The final theme looks at decision making regarding access to pornography.

Conclusion: The research offers an insight into how pornography within secure hospitals is managed. The research also provides an exploration into multi-disciplinary team decision making with regard to pornographic material and notes the general openness of staff towards patients having access to pornography. 


\section{Introduction}

The availability of pornography is ever increasing (Ferguson \& Hartley, 2009) and with this, researchers have begun to consider the effects of pornography exposure. Some research papers have reported the negative consequences of pornography, with particular focus on sexual aggression (Marshall, 2000). As such, concerns have been raised regarding the possible clinical issues related to pornography access in secure hospitals; predominantly those that house sexual offenders (Mercer, 2013) who already possess sexual deviant interests. The Fallon Inquiry (Fallon et al., 1999) brought the issue to the forefront of media attention and prompted a thorough review of all aspects of physical and relational security within high secure hospitals (Exworthy \& Gunn, 2003). The inquiry created a sense of scandal from the general public and perceptions of failure towards the risk management of offenders within a high security hospital. The Fallon Inquiry (1999) stressed the importance of controlling access to pornography as 'even apparently innocuous material can have a corrupting effect on individual patients' (recommendation 24; Fallon Inquiry, 1999, p.42) and if not controlled could result in a thriving trade in pornography. Furthermore, Duff (1995) invited the need for policy regarding pornography and censorship in secure hospitals. On the other hand, mental health services have seen a shift in their approach regarding the need to reduce restrictive practices and blanket rules (Department of Health, 2014). Thus, it may be difficult to strike a balance when it comes 
to pornography use. Patients residing in secure hospitals are seen to have the same needs for intimate relationships as everyone else, thus denying access to pornography can be seen as denying an expression of their sexuality (Perlin \& Lynch, 2014).

\section{Pornography and offending}

The notion of pornography comes hand in hand with concerns around the effect this material has on society. Despite the high volume of research, the causal link between pornography and offending is still confusing. Cook and Fosen (1971) found that convicted sex offenders reported less frequent exposure to pornography and exposure to less sexually explicit content than non-sexual offenders. Saramago et al. (2019) found that, while for some individuals pornography did not play a role in their offenses, there were others whose prolonged use led to more sex fantasies and urges to enact the visualized contents. As such, it is still very difficult to draw firm conclusions regarding whether this is a causal link or not. Theories such as the Social Learning Theory (Bandura, 1973) and Excitation Transfer Theory (Zillman, 1974) have been used to explain any possible link.

\section{Policing pornography}

Current policies on pornography use vary dramatically across different organisations. For example, West Minister NHS Trust has a detailed policy leaving decisions to staff discretion, whereas other Trust's fail to provide 
any policy at all (Nation Health Service, 2010, p.10). Such policies often value the choice of the individual but fail to exclusively dictate the exact role of staff who police pornography access. In turn, such-decision-making is often left to the discretion of those working within that service._-and assumes the service user is aware that 'most people do not behave as the people in the magazine or video would' (National Health Service, 2010; p.11).Furthermore, there are issues regarding the fact that a staff members presumably being-would be exposed to the pornography to determine whether it is suitable, resulting in the possibility that they may be negatively impacted. Mercer (2011) noted that the reviewing of pornographic material to determine its suitability often lies with nursing staff, as does the decision to restrict such items accordingly. Given this responsibility, it is concerning that prescriptive guidelines are not available to nursing staff to guide their decision making. On the other hand, nursing staff are committed to providing a duty of care and ensuring positive therapeutic engagement with offenders, where managing pornography is a daily component of care-planning and risk assessment, for those whom it may be a risk for.

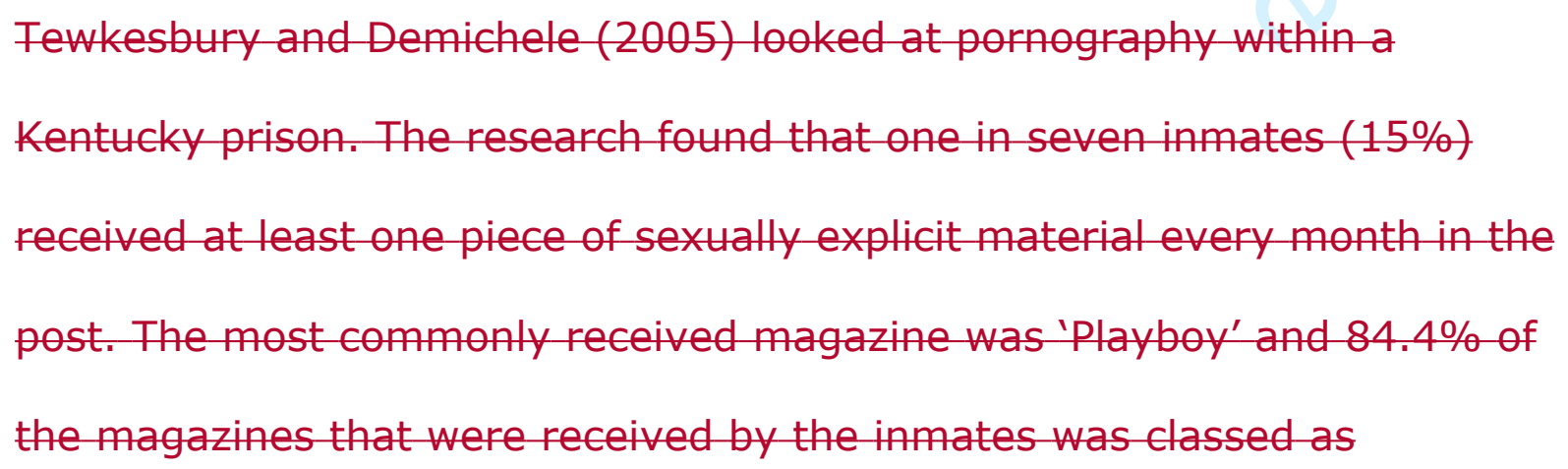


'mainstream' pornography. Mainstream pornography can be defined as "material that consists of sexual content of any shape or form (usually combines sex acts with the exposure of genitals) in images (pictures and/or acts) and words and where the goal of the material is to sexually arouse viewers or listener" (Corianos, 2007, p. 865). During the 12 month period that the study was completed, less than $1 \%$ of the inmates received magazines that were forbidden and which included illegal pornography (often illegal indecent images of children) or pornography that depicts 'force, bondage or physical injury to individuals' (p. 41). Regarding different convictions, violent offenders were the most likely to receive sexually explicit material (Tewkesbury \& Demichele, 2005). Thus, suggesting that in fact, sexual offenders do not access pornography more than other types of offenders.

\section{General Population Attitudes towards pornography}

Several researchers have directly explored attitudes towards pornography with a number of populations. Haggstrőm-Nordin and colleagues (2009) explored the attitudes of Swedish students towards pornography and found that male students reported more favourable attitudes towards pornography than female students. Female students were more likely to report concerns that pornography created a distorted image of sexuality than males (Haggstrőm-Nordin et al., 2009). Furthermore, Hald (2006) 
found that within a Danish sample both males and females reported generally positive attitudes towards pornography. Research within the US identified that most participants felt that they had learnt about how to have sex from watching pornography, and therefore viewed it as educational (Rothman et al., Kaczmarsky, Burke, Jansen, \& Baughman, 2015). Although some findings are mixed, in many research papers it is noted that men generally have more positive attitudes towards pornography than women.

\section{Professionals' Attitudes towards Pornography}

There has been some research with a focus on professionals' attitudes towards pornography consumption. Drake (1994) noted that $73 \%$ of university psychiatric nurse educators assessed felt that pornography trivialised rape and $38 \%$ believed that it stimulated consumers to commit sex crimes. However, of the 200 participants involved in the study, 93\% were not familiar with the literature related to the effects of pornography consumption. As such, it is likely that their perceptions of pornography were based primarily on their own experiences, beliefs and moral compass (Drake, 1994). Furthermore, this sample was a university-based sample of nurses and therefore not directly involved with patient care on a daily basis. A qualitative exploration by Mercer (2013) noted that male nurses were sympathetic to the needs of the offenders to access pornography. However, female nurses provided scenarios they had experienced, whereby pornography had been utilised by the patients and 
resulted in harassment and humiliation towards the women working on the ward. Mercer (2013) also noted that female nurses were content with those that had committed non-sexual offences to receive access to pornography, however, 'were resistant to the idea that those convicted of a sexual offence being entitled to the same rights' (Mercer, 2013, p. 20). Therefore, it appeared that within this study the attitudes of women to sexual offenders having access to pornography differed from males. Additionally, there were concerns with allowing a sexual offender access to pornography than other types of offenders. This provides further evidence for the importance of assessing the attitudes of staff in secure hospitals, to explore the relationships that attitudes have with the decision making in the institution.

Mellor and Duff (2019) found that staff members based their decisions regarding the patient's access to pornography on their own attitudes towards pornography. Therefore, if they had a negative attitude towards pornography then they were more likely to say 'no' to the patient having access. The research also indicated that staff were less likely to allow a sex offender access to pornography than when they were a violent offender or non-offender. Whether the staff member was male or female did not appear to predict their decision regarding whether the patient should have access to pornography.

\section{Decision making and risk management}


Researchers have explored how decisions are made within forensic mental health services, with specific focus on multi-disciplinary teams (MDT). In 1984, the Department of Health recommended that the profile of MDTs should comprise of psychologists, psychiatrists, nurses, social workers and occupational therapists when decisions are made-(Study Group on the Development of the Psychiatric Services, 1984). Professionals working in secure services often have to make decisions taking into account issues related to risk and security. Thus, striking a balance between the two is often challenging. "In an increasing risk-averse society, taking therapeutic risks becomes difficult to achieve" (Davies, 2004, p. 234). A recent study by Haines et al.,Perkins, Evans, \& McCabe, (2018) focused specifically on decision making in multi-disciplinary teams and found that decisions are often unequally shaped by the professional's own personal values and by the power dynamics linked to each member of the team. They noted that this may be because certain responsibilities are directly attributed to one individual within the MDT, such as the Responsible Clinician. Furthermore, nurses noted at times that their input in decision making was frequently overlooked, however, they were the ones often responsible for implementing team decisions and who had the most face-to-face contact with the patients (Haines et al., 2018). Although, Haines et al. (2018) do not mention pornography specifically, it is possible that the same process applies. 
A recent systematic review by Deering et al. (2019) explored what patients felt were beneficial with regards to their risk management. They noted that it was important that patients felt involved in the risk management plan in addition to their wider support network, such a families and friends. Thus, recommending that inclusion should form a major proportion of any risk management practices.

\section{Rationale}

Although much of the research looks at pornography use by offenders (Allen et al., 1999), very few papers focus on how this is applied into practice or make recommendations for decision making. There have been minimal attempts to consider the qualitative nature of pornography access (Mercer, 2013) in secure hospitals and often research looks at quantitative aspects (Drake, 1994; Mellor \& Duff, 2019). It is helpful therefore as researchers to understand the psychological underpinnings related to how staff working in secure hospitals make decisions about pornography use and the impact that their own attitudes towards pornography may have for risk management.

\section{Aims}

The aims of the study were:

- To explore the staff attitudes towards pornography use in secure hospitals.

- To explore how pornography use is managed in secure hospitals. 
- To understand the psychological underpinnings of how decisions regarding access to pornography are made.

\section{Method}

\section{Design}

This was a qualitative study which adopted a semi-structured interview. Thematic analysis is "a method for identifying, analysing, and reporting patterns (themes) within data" (Braun \& Clarke, 2006, p. 79) across a data set. This method allows for meaningful elements or codes to be combined to generate themes and explanatory models (Guest et al., $\bar{\top}$ MacQueen, \& Namey, 2012). The steps undertaken to ensure a rigorous thematic analysis of the study's data set are outlined here, and follow recommendations by Braun and Clarke (2006). As such, both researchers focused on the staff member's use of language within the identified themes. The transcripts were coded by one research separately and then discussions were had between the two regarding any discrepancies. Interfater reliability was calculated at .88 (Cohen's Kappa),

The current research project was approved by the University of Nottingham, Faculty of Medicine and Health Sciences Research Ethics Committee and the Research Ethics Committee at the service, in which the research was conducted. The service was a private sector hospital housing offenders and non-offenders in environments ranging from rehabilitation services up to medium security wards. 


\section{Participants}

Participants were recruited from a previous study conducted by the researchers (Mellor \& Duff, 2019). Following completion of that research project, participants contacted the researcher volunteering to be involved in a further interview to discuss their attitudes toward pornography within secure hospitals. Six participants volunteered to be involved in the research. This consisted of one male and five females aged 23-38 years (mean age $=28, \mathrm{SD}=5.37$ ). Participants were all staff members currently working within the secure hospital consisting of one Forensic Psychologist, one Trainee Psychologist, two Assistant Psychologists, one Clinical Information Administrator and one Speech and Language Therapist (see Table 1).

\begin{tabular}{|c|c|c|c|c|c|c|}
\hline \multicolumn{7}{|c|}{ Participant } \\
\hline & 1 & 2 & 3 & 4 & 5 & 6 \\
\hline Gender & Female & Female & Female & Female & Male & Female \\
\hline Age & 27 & 24 & 23 & 38 & 29 & 27 \\
\hline Job Role & $\begin{array}{l}\text { Assistant } \\
\text { Psychologist }\end{array}$ & $\begin{array}{l}\text { Clinical } \\
\text { Information } \\
\text { Assistant }\end{array}$ & $\begin{array}{l}\text { Assistant } \\
\text { Psychologist }\end{array}$ & $\begin{array}{l}\text { Speech } \\
\text { and } \\
\text { Language } \\
\text { Therapist }\end{array}$ & $\begin{array}{l}\text { Trainee } \\
\text { Psychologist }\end{array}$ & $\begin{array}{l}\text { Forensic } \\
\text { Psychologist }\end{array}$ \\
\hline Previous & No & No & No & Yes & Yes & No \\
\hline
\end{tabular}



personal use
pornography
Previous
Yes
Yes
No
Yes
Yes
Yes
exposure to
pornography
Attitudes
53
39
48
57
49
56
towards
pornography
score

Table 1: Participant Characteristics

From the attitudes to pornography scores it was noted that in general participants had a neither positive nor negative attitude towards pornography, except participant two, whose scores were slightly lower than the rest. This was reflected in participant two's qualitative responses in the interview.

\section{Procedure}

Participants were informed of the purpose of the research through information sheets. They were then provided with a consent form to sign. They were informed that interviews would be confidential to the researcher and research supervisor, but that interviews would be written up as part of the researcher's doctorate thesis and for potential publication. All participants agreed to have their discussion audio-recorded. 
Participants were then interviewed individually with one researcher present. The duration of interviews ranged from 45-70 minutes. Before beginning, participants were given verbal explanations of the project and given the opportunity for questions, thus helping participants feel at ease and building rapport with the researcher. Participants were given questionnaires to complete in order to gather demographic information; gender, age and job role. They were also asked to define pornography. Participants were then provided with definition of pornography by Hald, Malamuth and Yuen (2010); namely, 'sexually explicit materials intended to create sexual arousal in the consumer'.

Next, participants completed the Attitudes to Pornography Scale (ATPS; Evans-DeCicco \& Cowan, 2001) to measure their attitudes towards pornography. The Attitudes to Pornography Scale comprises of 13 questions and is rated on a seven-point Likert type scale. Answers ranged from strongly agree (7) to strongly disagree (1). Questions included 'pornography gives men false expectations about the opposite sex' and 'pornography is stimulating and exciting'. Higher overall scores on the ATPS indicated more positive attitudes to pornography. Scores on the scale could range from 13-91. This scale had adequate reliability with an alpha coefficient of .85 (Evans-DeCicco \& Cowan, 2001).

This ATPS scores were collected for further demographic information and all demographic data were used to describe the sample and to identify 
whether any of the participants has particularly positive or negative attitudes toward pornography and whether this was reflected in their qualitative responses. Participants were then asked semi-structured questions regarding pornography use and in particular its usage in secure hospitals. Questions were open-ended to allow a range of responses and to ensure that the participants did not feel uncomfortable being asked questions they did not know the answers to (Lurie, 2005). Thus, the interview explored:

- Personal feelings surrounding pornography

- Their experience of pornography use in secure hospitals

- Challenges or considerations that arise when making decisions regarding a patient's access to pornography

- The organisations policy and guidelines surrounding access to pornography.

At the end of the interview the participants were thanked for their participation and given a debrief sheet to take away with them.

\section{Ethical considerations}

Due to the sensitivity of the research topic, it was important to consider the ethical issues in order to protect and reassure the participants. Thus, all participants were provided with information prior to commencing the research regarding their anonymity. Participants were informed of their right to withdraw at any time and were told that any information gathered would be stored on a password-protected computer. Participants were 
only identifiable through a personal identification number. Participants were provided with a debrief sheet at the end of the research. This provided them with contact details for both the researcher and research supervisor. Additionally, participants were given internet links to websites for emotional support.

\section{Qualitative analysis}

The interview data were analysed using Thematic Analysis as guided by Braun and Clark (2006), by looking for recurring patterns in the data set. Within the thematic analysis the transcripts were analysed in an inductive way, as there was not a pre-existing framework with which to code the data. The thematic analysis looks at data at a latent level that goes beyond the semantic meaning of the data in order to interpret the underlying meanings of the data (Braun and Clarke, 2006). This was deemed as an appropriate method with which to analyse the data, as the transcripts represent the behaviours as they occurred in their natural environment and in real time and as such can be considered interpretations in the first iteration. Participants had volunteered on their own accord to be involved in the research with no reward.

Analysis was guided by Braun and Clarke's (2006) six-phase approach to thematic analysis as detailed below:

1. Firstly, it was important to become familiar with the data, which was achieved by repeated reading and re-reading of the data set following transcription.

Z. Next initial codes were generated, whereby interesting features of the data were coded manually and systematically across the entire data set. 
3. The initial codes were then grouped and potential themes were developed. These groupings were continually reviewed so a definition and exhaustive set of data to support each category was identified.
4. Next, themes were refined and the data were organised into dominant themes and associated subordinate themes. This stage also included re-reading of the data-set
5. Stage five included defining and naming themes. This revealed six dominant themes, e.g. controlling pornography, and 13 subthemes, e.g. boundaries and monitoring.
6. The last phase involved the final analysis and writing-up of the report.

\section{Results}

Six themes were identified from the data set and each superordinate theme then comprised of sub-ordinate themes (see Table 2). Each theme will be discussed in turn below. Where verbatim extracts have been used to illustrate analysis, participants are identified as Participant 1, Participant 2, etc. Ellipses have been used to denote where parts of a quote have been omitted due to irrelevance.

Table 2: Themes and Subordinate Themes

Themes

Subordinate themes

1. Attitudes toward pornography

2. Controlling pornography
Problems with relationships

False Expectations

Porn is for men

Boundaries

Monitoring 
3. Consequences for the patient

4. Patients are people

5. Individual propensities

6. Decision making
Positive consequences

Negative consequences

Human Rights

Blanket rules

Offence

Diagnosis

Impact of attitudes

The final decision

\section{Attitudes toward Pornography}

The first themeis theme explores the first aim of the research paper. There were three subordinate themes associated with the theme staff's personal 'attitudes towards pornography' explored staff attitudes toward pornography in general. These include the problems pornography may have on relationships, false expectations and the concept that pornography is something that mostly men engage with.

Problems with relationships 
Several participants reflecteddemonstrated throughout the interview the possible problems that they felt use of pornography could have on a person's intimate relationship.

"From experience of like talking to friends or whatever.... which can cause a rift between couples" (Participant 1).

"Interviewer: Do you think there are any negatives of using pornography? Participant 2: Erm I think obviously it depends on whether you are in a relationship or not erm I think some couples find it beneficial to use pornography to try and like stimulate the senses... but I think depending on the person I think other people would find it offensive if they found out that their partner in the relationship was using pornography" (Participant 2).

One participant also expressed the belief that pornography may be more suited to single people.

"I've never really felt the need to use pornography maybe because I've been in a relationship and I feel that only single people use pornography. (Participant 3).

The above demonstrates the possibility that the use of pornography could cause problems between couples. 


\section{False expectations}

A recurring theme participants expressed-was participants'their personal belief that viewing pornography could lead to a person developing false expectations.

"He would have an expectation of how women should perform" (Participant 1).

"It's quite easy for them to get into the wrong mind-set where sex actually comes about erm and how to treat women as well because I know from my own experience of watching videos the women are sort of degraded" (Participant 2).

"I think there's lots of stereotypes about you know the size of breasts and the sizes of penises" (Participant 4).

"Seeing stuff like that it does makes you I guess that kind of warped impression you get of what you'd expect and what's kind of considered normal" (Participant 5).

"I think for a lot of men it could give them unrealistic expectations of women" (Participant 6). 
One participant spoke about their belief that pornography use in general may reinforce negative beliefs.

\author{
"It's definitely giving off the wrong message to young boys and guys to \\ think that they could actually treat women the way that porn is \\ portrayed" (Participant 2).
}

These extracts demonstrate the concerns professionals have regarding the impact that pornography may have on people's attitudes toward sex and women.

\title{
Porn is for men
}

Participants raised A recurring pattern in the transcripts was the on-going belief that pornography is something that men use more than women. A belief that pornography is developed and consumed mainly for men. The participants look to provide an understanding and rationalisation for this.

"I don't know I feel like women don't use it as much as men, but I don't know why" (Participant 6).

"I've kind of often thought about why men are more prone to using it and I think maybe they are just a bit lacking in imagination and they need a visual stimulus whereas women can kind of conjure those images up for 
themselves and perhaps use masturbation without having to have that direct visual input" (Participant 4).

Here, one participant explains the difference in the use of pornography by men and women in terms of men's lack of imagination. This portrays an image that some people think that pornography is something that women don't use to the same extent as men. This may also be a result of society's views about pornography and women using pornography, as the literature related to pornography use focuses primarily on males as consumers rather than women.

\section{Controlling pornography}

The second theme looks at how access to pornography is controlled in secure hospitals. This theme addresses the second aim of the research. There were two subordinate themes associated with the theme 'controlling pornography'. These include: boundaries around pornography use, how the patient's use of pornography is managed and monitored including extreme usage of pornography.

\section{Boundaries}

Participants often spoke about the rules in place to manage pornography use by a patient. 


\begin{abstract}
"That person you know has some kind of expectation and boundaries round their use.... if you breach any kind of conditions that we've put in place i.e giving it to people that shouldn't be accessing it" (Participant 4).
\end{abstract}

\begin{abstract}
"We make sure that it's only for pornography and they don't explore any other websites" (Participant 2).
\end{abstract}

Participant 2 considers the viewing of pornography on the internet. The hospital's current policy regarding pornography suggests that a patient can access pornographic magazines or DVDs, however, does not consider the access of pornography using the internet.

The above extracts demonstrate the way in which staff manage the use of pornography on the wards and how boundaries are in place to ensure appropriate use of the material. Interestingly, however, only one participant was able to accurately state the organisation's current policy and procedures regarding access to pornography. The rest simply assumed what the policy may say or did not know that a policy even existed.

"No no idea (laughs) is there a policy?" (Participant 1). 
"I don't know officially what the policies are, but I know that it has been talked about on wards and I feel like everyone's a bit like doesn't quite know" (Participant 3).

The above therefore suggests that although many of the participants spoke about implementing boundaries regarding the patient's use of pornography, most, in fact, did not know about the boundaries currently stipulated by the policy, which is concerning.

\section{Monitoring}

A key issue within the transcripts was the use of different tools in order for staff to constantly monitor the patient's use of pornography.

"If we've got a baseline of their sexual behaviours say for 6 months then we'll give them we'll allow access to it and then we'll monitor ... we use like a scale that measures overt sexual behaviours" (Participant 6).

One participant reported the importance of nursing staff in ensuring the monitoring of pornography use.

\footnotetext{
"Nurses and Healthcare Assistants would likely be the ones that would pick up whether patients are abusing their use of pornography by lending it to other patients and monitor this as they are the ones that spend the
} 
most time around the patients so are able to pick up on these things" (Participant 6).

These reports demonstrate the importance staff place on the on-going process of monitoring pornography use after a patient has been granted access and ensuring that only the patient given access to the pornography is the one using it.

Alongside monitoring of pornography was the notion that patients have the potential to overuse pornography, if given access to it.

"I worked at XXXX hospital there was a guy who was very very sexualised already, we gave him access to pornography and then he masturbated 10 times a day" (Participant 6).

"You know they can't just watch it all day and then not go to their sessions" (Participant 4).

This demonstrated that staff were concerned that access to pornography could result in extreme usage, and that the patient may become oversexualised, which in turn could significantly impact on other areas of their life, such as treatment. As such, the monitoring of pornography use was considered important. 


\section{Consequences for the patient}

The third thee looks at There are two subordinate themes associated with the consequences for the patient if they could have access to pornography.

\section{Positive consequences}

Participants often spoke about the fact that patients are detained in a hospital setting to receive treatment and rehabilitation, and expressed the idea that pornography could form part of their rehabilitation process.

"That can kind of rehabilitate them I think that that's important and it shouldn't it shouldn't be taken away" (Participant 1).

"I would think if someone for example was from a more forensic background then maybe something could be used alongside it to make it more, I guess we are still a hospital setting so they should still have access to it but maybe some sort of sessions alongside it" (Participant 3).

"They should be educated about what is appropriate and why what they did was inappropriate and illegal" (Participant 1).

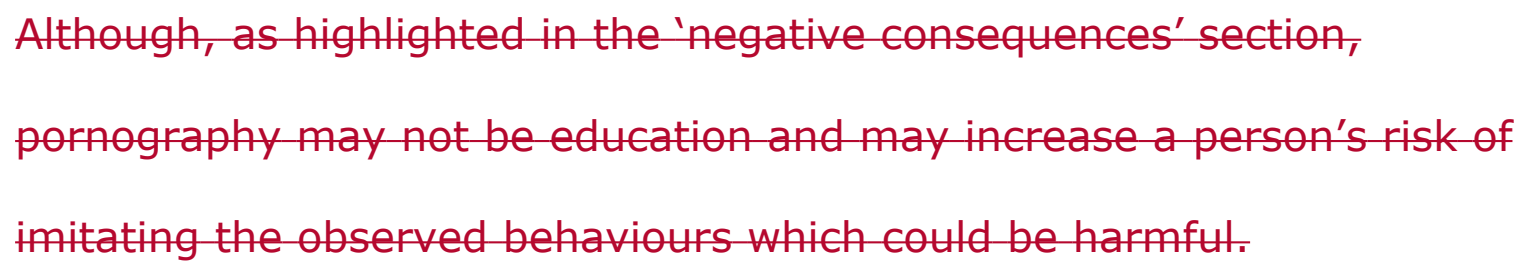


Commonly, participants referred to the idea that pornography could be used to normalise sex.

"I think it normalises sex for them" (Participant 5).

One participant also considered normalising the patient's life, whereby they may use pornography at home.

"I think in my experience it's been more of a normalising thing that men would access in the community and at home ...I think that it allows erm a bit of normality" (Participant 4).

Participants recognise that being in a hospital is not necessarily part of normal life and therefore the use of pornography can help them to feel more normal and living like they would in the community.

Participants often spoke about the use of pornography as a sexual outlet and a way for patients to release their sexual tension in a healthy manner.

"I think it can be used to alleviate that sexual tension...so I think as long as it's monitored and appropriate, they need to be able to kind of relieve that tension in an appropriate way" (Participant 1). 
"Certainly in secure settings it can be quite helpful to relieve that sexual tension" (Participant 5)

"Erm I think for some guys obviously they're locked up they they're not allowed to have sexual relationships but they still have a sex drive like any normal person does so I think for a lot of them it probably allows them to release sexual tension in a safe way if they're using it erm correctly" (Participant 6).

The above extracts demonstrate professionals' beliefs that access to pornography can help patients to reduce their sexual tension and be a healthy outlet to express their sexual desires.

\section{Negative consequences}

A number of participants expressed the notions they felt that patients were in hospital to get better and concerns that Thus, a recurring pattern across the transcripts was concerns that pornography consumption could make the patient worse, rather than better.

"He (patient) was given access to pornography and it massively increased his anger" (Participant 6). 


\begin{abstract}
"He (patient) would see pictures of naked women and stuff and it would lead to lots of sexual thoughts he will get very elated and then try and sexually assault people" (Participant 5).
\end{abstract}

The transcripts echoed a caution of giving a patient pornography that may cause them to deteriorate.

There was also the belief that this may be the case for a patient having access to pornography.

"Erm I think a lot of guys who have committed sexual offences they already have negative attitudes towards women and I think it probably does reinforce them" (Participant 6).

There was also a concern that patients may imitate the behaviours observed within the pornography.

"They're more likely to kind of read into that and take that as kind of gospel that that's what sex is and kind of copy things that they see in porn" (Participant 5).

"I consider where there is any kind of correlation between what they are asking for and staff on the ward is it kind of a sexual enactment thing" (Participant 5). 
This demonstrates the belief that observing a behaviour that is deemed as enjoyable sexually may result in a person re-enacting that behaviour in real life. Thus, concerns were expressed over areas that might relate to risk.

\section{Patients are people}

This theme explored the way in which the participants recognised that the patients were still human beings. Two-subordinate themes were associated with the theme of 'patients are people'. These relate to the idea that pornography access could be a human right, the notions that everyone should have individualised care and that there should be no blanket rules.

\section{Human rights}

Participants spoke at times about everyone having a right to pornography and that a patient residing in a secure hospital should be no different.

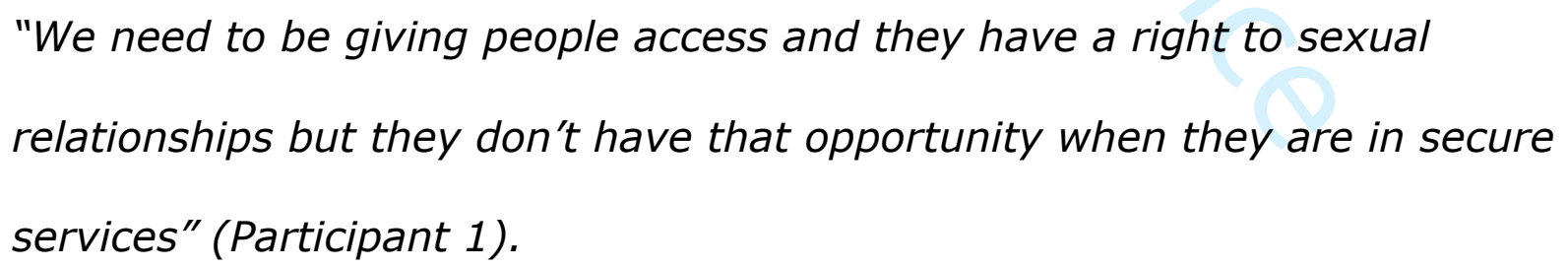
relationships but they don't have that opportunity when they are in secure services" (Participant 1). 
"I think it is within the patient's rights to have access to pornography, like us and them, we're all humans and we have needs to fulfil" (Participant 2).

"I guess we are still a hospital setting so they should still have access to it but maybe some sort of sessions alongside it" (Participant 3).

The above reflects how participants view accessing pornography as a basic human right and how a patient being in a hospital should not affect this right. However, one participant recognises that pornography use needs to be structured in order to reduce the potential negative consequences.

The current service policy considers pornography within the context of human rights and states "legally, the charity should make reasonable provisions for a patient's access to sexually explicit material...a person's access to pornographic material which is their own property is an aspect of their personal life. A person's sexual life is protected by Article 8 European Convention of Human Rights therefore any interference with the exercise of this right must be proportionate and go no further than necessary". This suggests that if a person living in the community can look at legal pornography, and if there is not a good enough reason to prevent someone in hospital from doing so, then they should be allowed the same. 


\section{Blanket rules}

A recurring theme from the interviews was the notion that all patients should receive indiviudalised care that is tailored to their personal needs.

"It would need to be agreed beforehand to be sure that there is nothing inappropriate going on there and it's kind of on an individual basis" (Participant 1).

"I think taking into consideration more individual factors but I don't think necessarily anyone should be ruled out" (Participant 3).

"I think it's something that needs to be accessed individually because I think for some erm individuals it would be absolutely not appropriate" (Participant 4).

A desire to avoid implementing 'blanket rule' was expressed.

"For them to have something to have access to rather than just having a blanket ban and saying no you can't have sex whilst you're here which is a bit of an unrealistic expectation" (Participant 4).

"I think it's something that shouldn't be like a blanket availability just to anyone I think it should be kind of very individualised" (Participant 5). 
Others spoke about taking positive risks.

"I think that everyone's got to have an opportunity to see whether it is or isn't suitable" (Participant 6).

"I think in most cases we'll take a positive risk and allow them to have it" (Participant 6).

The comments made by the participants suggest that staff are aware of the needs that patients may have and are avoiding using restrictive practices to accommodate to specific individuals.

\section{Individual Propensities}

This theme looked at individual propensities that the participants considered. The theme of individual propensities is made up of two subordinate themes. These include the patient's offence and diagnosis.

\section{Offence}

The offence of the patient was discussed in many of the transcripts and appears to play a key role in the staff's discussions around pornography use. 


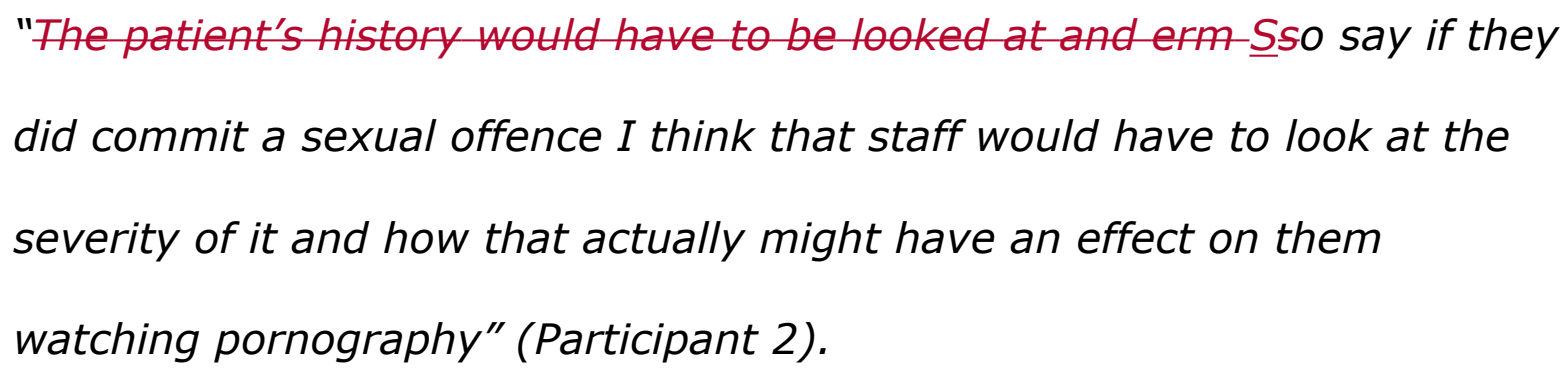

"Especially with sexual offences, I think that probably comes a lot in the decision making" (Participant 3).

I think for particular patients with a history of erm paedophilia or people with kind of violent sexual tendencies" (Participant 4).

"Personally I would struggle with the thought of a paedophile having access to pornography" (Participant 5).

The consensus from the participants was that there was a more cautious approach to allowing a patient who had committed a sexual crime access to pornography.

\section{Diagnosis}

The diagnosis often plays a role in the dialogue of the participants when discussing a patient's access to pornography. 
"I work in a Huntington's disease ward where it is more about quality of life so for men on that ward we would be more likely to give them access to pornography than maybe on another ward" (Participant 3).

"So you know working with young males particularly with ASD, you get a lot of patients who are high functioning ... so it's really quite appropriate" (Participant 4).

"Erm I think it gives particularly men with learning disabilities a lot of them haven't had sexual experiences" (Participant 6).

The above extracts highlight how the diagnosis of the patient appears to play an important role in determining whether a patient should have access to pornography or not.

\section{Decision making}

This theme The third aim of the research explores how decisions regarding access to pornography are made. The theme decision making is comprised of two subordinate themes. These include the impact of attitudes and the final decision.

The impact of attitudes 
When talking about decision making regarding a patient's access to pornography, participants often spoke about how different staff members own attitudes would influence the decision making.

"Personally I would struggle with the thought of a paedophile having access to pornography" (Participant 5).

"At the moment I work with a social worker who is quite erm I don't know what the right word it, I don't want to say prudish but she's quite traditional and she's got quite strong views about how things should be run and getting her to come round to the idea of allowing sexual offenders pornography I think is quite difficult" (Participant 6).

The above extract demonstrates that in MDT meetings different professionals have differing opinion and may be based on their own moral judgement, rather than taking a more objective approach.

The final decision

When discussing who had the final decision regarding whether a patient does or does not have access to pornography it appears that Psychologists play a crucial link, due to their knowledge of forensic issues and the patient's risk history. 
"I (Psychologist) would be the one that primarily has more in-depth knowledge about their sexual risk...I do think quite often that the team rely heavily on you as a Psychologist to inform their decision quite heavily...I think a lot of it does fall to you and it's about you being able to persuade the team either way whatever you think really" (Participant 6).

Although, key professionals played a significant role in the decision making, ultimately the final decision was a team decision.

"I don't think we always come to an agreement I think perhaps there has been a split and we've talked about it and we've come to a decision as a team...we would make the decision as a team, as we do with most decisions" (Participant 6).

Thus, the use of MDTs and making the decision as a team appears to be an important process within the decision making. It is possible that the use of a MDT could reduce the likelihood of bias from an individual's own attitudes. That is unless the majority share the same bias.

\section{Discussion}

Thematic analysis of the interview transcripts yielded six themes that provided an insight into the attitudes of staff members towards pornography use within secure hospitals and how such decisions are made. Presently, there is minimal research within this area, therefore 


\section{little is known about the attitudes of staff who are likely to make such decisions regarding pornography access.}

Theme One - Attitudes toward Pornography

\section{Theme one focused on the participants' attitudes toward pornography in}

general. Although participants completed the Attitudes toward

Pornography Scale (Evans-DeCicco \& Cowan, 2001), which indicated neither positive nor negative attitudes towards pornography, during the interview they highlighted a number of concerns related to pornography. Participants considered personal experiences of pornography having a negative impact on relationships. They also noted the possibility that patients watching pornography may develop unrealistic expectations of relationships or sex. There was the ongoing belief that pornography is something that men generally use rather than women. This is mirrored within the literature (Haggstrőm-Nordin et al., 2009). Interestingly, four of the six participants had been exposed to pornography, meaning that they have seen pornographic material, however, only two participants admitted to using pornography. This therefore may have been influenced by the stigma associated with pornography or the fact that a majority of the participants were female. Thus, such viewpoints may be considered when clinical teams have discussions regarding a patient accessing pornography, particularly as previous research suggests that personal attitudes influence decision making (Mellor \& Duff, 2019). 
Theme Two - Controlling Pornography

The second theme looks at how staff control the patient's use of pornography. This theme provides an understanding of how staff would ensure that there are boundaries in place in order to monitor and manage the use of pornography by patients within a secure hospital. It emerged that staff regularly review the patient's use of pornography to determine whether it is appropriate, and monitor their behaviour once given access to pornography. This ensures that they are aware of any potential impact on their level of risk and any inappropriate use such as extreme usage. Consequently, staff were generally keen to allow patients access to pornography within the parameters of a robust risk management and behavioural observation plan, in line with reducing restrictive practices (Department of Health, 2014). Within the service policy are boundaries regarding pornography use, including "sexually explicit material should be kept in the patient's room for personal and private use". However, only one participant in the study was aware of the policy. This is particularly concerning given that these participants may be involved in discussions regarding a patient's access to pornography but in fact do not know what the policy suggests. Drake (1984) highlighted the need for clear policy regarding pornography use, however it appears that even with a policy being in place that it is not being used.

Theme Three - Consequences for the Individual 
The third theme 'consequences for the individual' explores both the potential positive and negative consequences of a patient having access to pornography. This theme explores incorporating the use of pornography within treatment. Johnson (2015) noted that some probation officers were doing just that. Although this is not common practice, they felt that soft core pornography could support sexual offenders to redefine and recondition their sexual arousal and interests to more appropriate content.Johnson (2015) explored the use of pornography within the treatment of sexual offenders and noted that pornography use with sexual offenders may trigger the offender's memory about their offending. Furthermore However, there is no empirical evidence supporting the use of pornography within treatment (Johnson, 2015). Wright, Tokunaga, \& Kraus, (2015) found that there was a positive association in general populations between pornography use and sexual aggression. Thus, it is understandable that staff have some concerns about the negative consequences of pornography. The theme raised concerns regarding the impact that pornography use could have on the patient's attitudes towards women and in turn their behaviour. Concerns included the possibility of the patient imitating the behaviour (Bandura, Social Learning Theory, 1973). It may also be that the use of pornography may increase their sexual preoccupations. This theme demonstrates the staff members' apprehension about pornography due to the concerns that it could make people worse. However, it also 
demonstrates the professionalism of staff, being open to the idea of pornography use to normalise sex.

\section{Theme Four - Patients are People}

The fourth theme of 'patients are people' looks at staff members' ability to recognise that patients have similar needs to anyone else with regard to intimate relationships (Perlin \& Lynch, 2014). The theme puts real emphasis on the movement at present in secure hospitals to reduce restrictive practices and take a more individualised approach to patient care. This mirrors the advice provided by the Department of Health (2006) regarding reducing service-level restrictions. Furthermore, Mercer (2013) noted "from the perspective of ethical practice, restriction can be interpreted as positive intervention or breach of human rights" (p.15). Interestingly, participants considered pornography to fall within human rights, however, other items such as alcohol and nicotine are not considered human rights. This is likely because sexual needs are seen as something all humans experience and therefore have a right to express their sexuality (Perlin \& Lynch, 2014). This theme considers the patient's right to access pornography but recognises the needs for this to be boundaried to reduce any potential negative consequences of pornography. This is important as this research supports the clinical change to treat patients the same as if they were living out in the community and the movement away from using blanket rules. The theme overall appears to illustrate a positive attitude towards pornography use 
in secure hospitals, guided by risk management. Therefore, reducing the likelihood of restrictive practice and demonstrating an openness to consider the individual needs of the patients, as well as promoting a positive quality of life.

Theme Five - Individual Propensities

The fifth theme 'individual propensities' focused on the vulnerability of the patient which may put them more at risk of being negatively affected by pornography. These included issues related to mental health diagnosis and their previous offending history. There was a consensus from the participants that patients who had a previous history of sexual offending may be more vulnerable to negative effects of pornography. Therefore, as clinicians we need to think more about the way we treat sexual offenders in relation to pornography. Marshall (2000) identified that exposure to pornography may influence the development of sexual offending in some men, however, they also noted that for most men who sexually offend the use of pornography is a manifestation of already sexually deviant interest. Furthermore, it can be difficult to draw firm conclusions regarding the impact of pornography on different individuals when the research in this area is so contradictory (Mellor \& Duff, 2019). Linking with theme threewo, it may be that pornography could be incorporated into treatment programmes. Johnson (2015) noted that some probation officers were doing just that. Although this is not common practice, they felt that soft core pornography could support sexual offenders to redefine and 
recondition their sexual arousal and interests to more appropriate content. However, the literature underpinning this is lacking and in fact other researchers suggest that pornography use increases risk (Malamuth, Addison, \& Koss, 2000). Services may be cautious about how society may view a sexual offender having access to pornography, as happened in the Fallon Inquiry (1999) and the possible backlash from this. However, from the data sets it appears that staff are open to the idea of pornography which may lead to less restrictive practices in relation to a patient's access to pornography.

\section{Theme Six - Decision Making}

The final theme 'decision making' addresses the third aim of the research to focus on the way in which staff make decisions regarding access to pornography. This looked particularly at the influence of attitudes towards pornography on decision making and who generally has the final decision. Staff were able to recognise the impact that negative attitudes towards pornography could have regarding MDT discussions. However, positively, they were able to identify that any subjectivity is generally balanced out by making the decision as a team. Previous literature suggests that decision making within MDTs is often unevenly weighted and that the Responsible Clinician has primary responsibility (Haines et al., 2018), whereas this did not appear to be the case within this research. Thus, suggesting that decision making considers all professional opinions and experience rather than being unevenly weighted towards one member of 
the team. This, therefore, could improve clinical practice, and allow members of the team to feel valued and important as well as reducing possible biases. Interestingly, none of the participants considered involving the patients in the decision making or risk management process despite research indicating that patients find this beneficial (Deering et al., 2019).

Overall, the research aims to gain an understanding into staff attitudes towards pornography within secure hospitals, how pornography use is managed and how decision making is achieved. The research-provides encouraging results regarding staff attitudes towards pornography use within secure hospitals but suggests that there is some overlap between attitudes towards pornography and decision-making regarding access to pornography. The research indicated that $\underline{S}$ staff generally have a liberal and open view towards the use of pornography within such settings, however, that they have concerns regarding sex offenders having access to pornography, as demonstrated within previous literature (Mercer. 2013). Alongside this comes issues with regards to pornography-in general and its use of violence in a large number of pornographic productions (Bridges et al. 2013), therefore possibly reinforcing sexual offenders pre-existing beliefs about the use of violence during sex. Interestingly, although policy and guidelines regarding the use of pornography in secure hospitals was available, only one participant was able to demonstrate an awareness of the policy. This highlights possible 
concerns that decisions are being made without the use of policies which are aided to guide decision making. Thus, recommendations may be to healthcare services to ensure that their staff are aware of current policies related to pornography use. However, as noted by Mercer (2010), the reviewing of pornographic material is often completed by nursing staff and unfortunately no nursing staff volunteered to be included within this study. It is also recommended that when making decisions regarding access to pornography that the patient is included in this process (Deering et al., 2019).

Interestingly none of the participants spoke about the issues that come with the production of pornography material. Research using the selfobjectification theory noted that women begin to view themselves as sexual objects as a result of pornography (Tykla \& Kroon Van Diest, 2014). Objectification theory (Fredrickson \& Roberts, 1997) serves as a useful framework for studying sexual objectification among women. This theory specifies that being sexually objectified encourages women to adopt an observer's perspective of their body (i.e., to self-objectify), which is damaging to their wellbeing in a multitude of ways. Furthermore, women used in the production of pornography are often subject to violence and coercion during filming (Hughes, 2010). However, none of the participants in this study discussed these issues, focusing primarily on the impact of pornography on the patient's risk. 


\section{Clinical Implications}

The research highlights that pornography use in secure hospitals can be a contentious issue which presents an array of opinions and concerns. This study notes the importance of staff having an awareness of their own attitudes and challenging these to ensure that it does not impact on their decision making. With regard to professional practice, this-This research aims to provide an understanding of decision making and in a hope to continuinge the movement away from restrictive practices. The topic of pornography access, with sexual offenders, can cause anxiety within staff. The research emphasises that pornography use within secure hospitals is not something to shy away from and that pornography use can have its benefits, if used appropriately, correctly monitored and risk managed. Patients detained in secure hospitals have a range of complex issues and needs and therefore it is essential that staff take a collaborative and positive approach to their treatment in the least restrictive form. However, as demonstrated from the research this may be hindered by the staff member's own attitudes towards pornography, as there appears to be a dilemma between their personal views and the need as a clinician to promote free choice. Thus, providing further evidence for the need to make decisions regarding patient care objectively (such as offence paralleling behaviours) rather than on their own subjective feelings.

\section{Strengths and Limitations}


One strength about this research is that it is the first piece of research to date that directly explores several attitudes towards pornography and provides an understanding of how pornography is managed and how decisions regarding access to pornography are made within secure hospitals with a range of staff members. Whereas previous research, Mercer (2013), focused in particular on mental health nurses views regarding sexual offenders having access to pornography and did not measure their attitudes toward pornography in general.

However, there are a number of limitations to this study. It is noted that the study used a small sample which limits the reliability of the results. Additionally, s-Some of the participants may not have a direct influence in decision making. Thus, future research should endeavour to include nursing staff within the sample. Furthermore, volunteers for the research were predominantly female staff. Thus, the result may be biased and the results make therefore be vulnerable to gender differences. It would therefore be useful to explore why more males did not volunteer to help with the research. It may be that females are generally more likely to volunteer than males (Shelton et al., 2013). Moreover, a further limitation may be the fact that the participants spontaneously contacted the research following participating in an earlier research project. Therefore these participants are likely to be a subgroup of staff and may not be typical of a general staff sample, as it is likely they may have selfselected as a result of having strong opinion in the area. Thus, there 
could be a possibility of selection bias. Any conclusions drawn from the research are not representative to staff working in secure hospitals as a whole and should be interpreted with caution.

\begin{abstract}
Although the questions did not focus on gender in relation to the patient's pornography access, all-All participants only-worked with male patients and therefore their responses and experiences focused on pornography use with male patients. Therefore, this limits the generalisability of the results to the use of pornography with male patients. However, there is no research to date exploring the use of pornography by females in secure hospitals. Finally, the interview schedule included some closed questions. As such it is possible that this could have limited the discursiveness for the participants.
\end{abstract}

\title{
Future research
}

Future research should attempt to include more male participants s into the sample to rule out any possible confounding variable of gender. Furthermore, asand nursing staff-are often the ones that implement decisions on a day to day basis it would be useful to include these within the sample. All participants involved in the current study worked with male patients, therefore future research could include participants that work with female patients to see whether there is a difference. 


\section{Conclusion}

The present research study provides an insight into the experiences of staff working in secure hospitals and their attitudes towards pornography use within such a setting. The research was of particular interest considering the changes within the Department of Health (2014) to reduce restrictive practices within secure hospitals. The study aimed to build upon research regarding this population which appear to be underrepresented within the literature, and thus this research contributes towards this. The current study also provides a foundation for future investigation however; the limitations above points to several areas that are still in need of further exploration and highlight a need to make professionals aware of current policies related to pornography.

\section{Implications for practice}

- Teams making decisions regarding access to pornography should do this collaboratively and involve the patient.

- Services to ensure all staff are aware of any policy regarding pornography.

- Staff to be aware of the impact of their own attitudes.

References

Allen, M. D'Alessio, D., \& Emmers-Sommers, T. (1999). Reactions of Criminal Sexual Offenders to Pornography: A Meta Analytic Summary. Annals of the International Communication Associations, 22(1), 139-169 
Bandura, A. (1973ㄱ). Social learning theory. Englewood Cliffs, NJ: Prentice Hall.

Braun, V., \& Clarke, V. (2006). Using thematic analysis in psychology. Qualitative research in psychology, 3(2), 77-101.

Bridges, A. J. Wosnitzer, R. Scharrer, E. Sun, C., \& Liberman, R. (2010). Aggression and sexual behavior in best-selling pornography videos: $A$ content analysis update. Violence Against Women, 16(10), 1065-1085.

Cook, R. F., Fosen, R. H., \& Pacht, A. (1971). Pornography and the sex offender: Patterns of previous exposure and arousal effects of pornographic stimuli. Journal of Applied Psychology, 55(6), 503511.

Corsianos, M. (2007). Mainstream Pornography and "Women": Questioning Sexual Agency. Critical Sociology, 33, 863-885

Davies, S. (2004), "Secure psychiatric services", in Campling, P., Davies, S. and Farquharson, G. (Eds), From Toxic Institutions to Therapeutic Environments. Residential Settings in Mental Health Services, 1st ed., London Royal College of Psychiatrists, London, 233-43.

Deering, K., Pawson, C., Summer, N., \& Williams, J. (2019). Patient perspectives of helpful risk management practices within mental health services. A mixed studies systematic review of primary research. Journal of psychiatric and mental health nursing.

Department of Health (2014). Positive and proactive care: reducing the need for restrictive interventions. London: Stationary Office. 
Drake, R. E. (1994). Potential health hazards of pornography consumption as viewing by psychiatric nurses. Archives of Psychiatric Nursing, 8(2), 101-106

Duff, A. (1995). Pornography and censorship: The problems of policy formation in a psychiatric setting. Psychiatric Care, 2, 137-140.

Evans-DeCicco, J. A., \& Cowan, G. (2001). Attitudes toward pornography and the characteristics attributed to pornography actors. Sex roles, 44(5), 351-361.

Exworthy, T., \& Gunn, J. (2003). Taking another tilt at high secure hospitals - The Tilt Report and its consequences for secure psychiatric services. The British Journal of Psychiatry, 182, 469-471.

Fallon, P., Bluglass, R., Edwards, B. \& Daniels, G. (1999). Report of the Committee of Inquiry into the Personality Disorder Unit, Ashworth Special Hospital. Cm 4194. London: HMSO.

Ferguson, C, J., \& Hartley, R. D. (2009). The pleasure is momentary... the expense damnable? The influence of pornography on rape and sexual assault. Aggression and Violent Behaviour, 14, 323-329

Fredrickson, B. L., \& Roberts, T.-A. (1997). Objectification theory: Toward understanding women's lived experiences and mental health risks. Psychology of Women Quarterly, 21, 173-206.

Guest, G., MacQueen, K. M., \& Namey, E. E. (2012). Applied thematic analysis. Thousand Oaks, CA: Sage 
Häggström-Nordin, E., Tydén, T., Hanson, U., \& Larsson, M. (2009). Experiences of and attitudes towards pornography among a group of Swedish high school students. The European Journal of Contraception \& Reproductive Health Care, 14(4), 277-284.

Haines, A. Perkins, E. Evans, E. A., \& McCabe. R. (2018). Multidisciplinary team functioning and decision making within forensic mental health. Mental Health Review Journal, 23(3), 185-196

Hald, G. M (2006). Gender differences in pornography consumption among young heterosexual Danish adults. Archives of Sexual Behaviour, $35,577-585$

Hald, G. M. Malamuth, N. M., \& Yuen, C. (2010). Pornography and attitudes supporting violence against women: Revisiting the relationship in nonexperimental studies. Aggressive Behavior: Official Journal of the International Society for Research on Aggression, 36(1), 14-20

Hughes, D. M. (2010). Sex trafficking of women for the production of pornography. Citizens Against Trafficking.

Johnson, S. A. (2015). The Use of Pornography with Sex Offenders in Treatment: A Controversial Conundrum. Journal of Forensic Research, $6(5), 1-6$

Malamuth, N. M., Addison, T., \& Koss, M. (2000). Pornography and sexual aggression: Are there reliable effects and can we understand them? Annual review of sex research, 11(1), 26-91.

Marshall, W. L. (2000). Revisiting the use of pornography by sexual offenders: implications for theory and practice. Journal of Sexual Aggression, 6, 6777 
Mellor, E., \& Duff, S. (2019). The use of pornography and the relationship between pornography exposure and sexual offending in males: A systematic review. Aggression and Violent Behavior, 46, 116-126

Mercer, D. (2011). Policing pornography in high-secure care: The discursive construction of gendered inequality. ( $R e)$ thinking Violence in Health Care Settings: A Critical Approach, 235.

Mercer, D. (2013). Girly mags and girly jobs: pornography and gender inequality in forensic practice. International Journal of Mental Health Nursing, 22, 15-23

Perlin, M. L., \& Lynch, A. J. (2014). 'All his sexless patients': persons with mental disabilities and the competence to have sex. Washington Law Review, 89(2), 1-37.

Rothman, E. F. Kaczmarsky, C. Burke, N. Jansen, E., \& Baughman, A. (2015). "Without porn...I wouldn't know half the things I know now": A qualitative study of pornography use among a sample of urban, lowincome, black and Hispanic youth. Journal of Sex Research, 52(7), 736746

Saramago, M. A., Cardoso, J., \& Leal, I. (2019). Pornography Use by Sex Offenders at the Time of the Index Offense: Characterization and Predictors. Journal of sex \& marital therapy, 1-15.

Shelton, L., Stone, J., \& Winder, B. (2013). Evaluating the factor structure and reliability of the community attitudes toward sex offenders (CATSO) scale. Journal of Criminal Psychology, 3(2), 115-26. 
Tewkesbury, R., \& Demichele, M. (2005). Porn in Prison: How does it get in? Who receives it? Journal of Offender Rehabilitation, 42(2), 35-48.

Tylka, T. L., \& Kroon Van Diest, A. M. (2015). You looking at her "hot" body may not be "cool" for me: Integrating male partners' pornography use into objectification theory for women. Psychology of Women Quarterly, 39(1), 67-84.

Wright, P. J., Tokunaga, R. S., \& Kraus, A. (2015). A meta-analysis of pornography consumption and actual acts of sexual aggression in general population studies. Journal of Communication, 66(1), 183-205. 